\title{
Canadian adolescents and young adults with cancer: opportunity to improve coordination and level of care
}

\author{
Prithwish De PhD, Larry F. Ellison MSc, Ronald D. Barr MB ChB MD, Robert Semenciw MSc, \\ Loraine D. Marrett PhD, Hannah K. Weir PhD, Dagny Dryer MD, Eva Grunfeld MD DPhil; \\ for the Steering Committee for Canadian Cancer Statistics
}

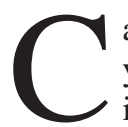
ancers in adolescents and young adults (aged 15-29 years) represent a transition between the nonepithelial types, especially acute leukemias and embryonal tumours, that are common during childhood and the epithelial types (i.e., carcinomas) that account for most cancers in older adults. The embryonal tumours that are common in children, such as neuroblastoma, Wilms tumour, retinoblastoma, medulloblastoma and hepatoblastoma, are rare among adolescents and young adults. Similarly, the most common carcinomas in older adults, such as lung, breast, prostate and colorectal cancers, have a much lower incidence among young people. The differences relative to other age groups is such that the classification system used to report cancer incidence in adolescents and young adults is a blend of those used for cancers in childhood and adult life. ${ }^{1}$

Adolescents and young adults account for about $2 \%$ of all patients with a new diagnosis of invasive cancer in Canada. ${ }^{2}$ Although the annual number of cases is small relative to those in older adults, a diagnosis of cancer during adolescence or young adulthood can have a major impact on future quality of life and life expectancy, as well as disrupting normal trajectories of development (e.g., physical, psychological and social) and life goals related to family and careers. ${ }^{3}$ Selfimage among young cancer patients can be compromised by the adverse effects of therapy (e.g., loss of hair, gain or loss of weight, impairment of sexuality, mutilating surgery). Social relationships are also challenged by the strain caused by a diagnosis of cancer and subsequent therapy. Medical professionals are often ill-equipped to deal with the psychosocial challenges faced by young people with cancer.

Our objective was to examine current Canadian data on cancer in adolescents and young adults and to review the literature on the obstacles that patients in this age group face in receiving adequate care.

\section{Methods}

We obtained cancer incidence data from the July 2009 version of the Canadian Cancer Registry, a dynamic, populationbased database maintained by Statistics Canada. The Can adian Cancer Registry contains information on cases diagnosed from 1992 onward, based on reports from every provincial and territorial cancer registry. Cases from this data-

\section{Key points}

- Between 2002 and 2006, an average of 2252 new cases of cancer were diagnosed every year among adolescents and young adults.

- Little is known about the risk factors for many of the leading cancers in this age group, which makes prevention difficult.

- Several Canadian and international initiatives are addressing the major treatment and care issues faced by this age group, including diagnostic delays and lack of age-appropriate care.

base are routinely linked at the national level to identify persons with more than one primary tumour. We classified incident cancers in adolescents and young adults according to the morphology-based classification system proposed by Birch and colleagues. ${ }^{4}$ This system uses 10 major diagnostic groups defined by the International Classification of Diseases for Oncology morphology codes. We obtained mortality data from the Canadian Vital Statistics - Death Database, also maintained by Statistics Canada. These data are based on information provided by the vital statistics registrars in each province and territory. We obtained population estimates from Statistics Canada's Demographics Estimates Compendium 2008.

We report here the number of new cancer cases for the most recent five years of available data (2002-2006). Incidence rates were available for 1992-2006, and we examined overall trends, as well as trends for individual cancers, for the period 1997-2006 (i.e., the most recent 10 years of available data). We report the number of deaths for the most recent five years of data (2001-2005). Mortality rates were available for

From Cancer Control Policy and Information (De), Canadian Cancer Society, Toronto, Ont.; the Health Statistics Division (Ellison), Statistics Canada, Ottawa, Ont.; McMaster University and McMaster Children's Hospital (Barr), Hamilton, Ont.; the Centre for Chronic Disease Prevention and Control (Semenciw), Public Health Agency of Canada, Ottawa, Ont.; Surveillance and Population Studies (Marrett), Cancer Care Ontario, Toronto, Ont.; the US Centers for Disease Control and Prevention (Weir), Atlanta, USA; the PEI Cancer Treatment Centre (Dryer), Charlottetown, PEl; and the Ontario Institute for Cancer Research (Grunfeld), Toronto, Ont. Members of the Steering Committee for Canadian Cancer Statistics are listed at the end of the article.

CMAJ 2011. DOI:10.1503/cmaj.100800 
1992-2005, and we examined trends for 1996-2005 (i.e., the most recent 10 years of available data). We calculated annual percent changes to indicate changes in incidence over the period 1997-2006 and changes in mortality rates over the period 1996-2005.

We restricted the survival analyses to first primary tumours only. We excluded persons whose diagnosis was established through either death certificate only or autopsy only because we could not determine the date of diagnosis for these individuals. We determined each person's vital status by linking records to the Canadian Vital Statistics - Death Database and using information reported by provincial and territorial cancer registries. At the time of our analysis, follow-up for vital status was complete through December 31, 2005.

We conducted survival analyses for 2001-2005 using period analysis. ${ }^{6}$ A period analysis is defined by the survival experience of people in a recent time interval. The period estimates reported here should be interpreted as predictions of survival for cases diagnosed from 2001 to 2005, since the "true" survival for such cases will not be known until followup for vital status is complete through 2010. The period analysis method allows more up-to-date survival estimates to be derived than would be possible using traditional cohort methodology. ${ }^{7}$ Several studies,${ }^{8-11}$ including one employing data from the Canadian Cancer Registry, ${ }^{8}$ have empirically evaluated this method, with favourable results. Estimates of survival derived through period analysis have often been slightly pessimistic in estimating the long-term survival of patients with recently diagnosed cancer, particularly for cancers with recent rapid improvement in survival over time..$^{8-11}$ We report here observed survival proportions, referring to the proportion of young people with cancer alive after a given length of time (e.g., 5 years) since diagnosis.

\section{Results}

\section{Incidence, mortality and survival}

On average, there were 2252 new cancer cases among adolescents and young adults per year in Canada between 2002 and 2006, which corresponds to an annual incidence rate of 347.2 per million (Table 1). Incidence increased with age, such that those aged 25 to 29 years were 2.5 times more likely to receive a diagnosis of cancer than those aged 15 to 19 years.

Table 1: Number of new cases and average annual incidence rate (per million) for adolescents and young adults (15-29 years), by sex and age group, Canada, 2002-2006*

\begin{tabular}{|c|c|c|c|c|c|c|}
\hline \multirow[b]{2}{*}{$\begin{array}{l}\text { Age, } \\
\text { yr }\end{array}$} & \multicolumn{2}{|c|}{ Male } & \multicolumn{2}{|c|}{ Female } & \multicolumn{2}{|c|}{ Both sexes } \\
\hline & $\begin{array}{l}\text { New } \\
\text { cases }\end{array}$ & $\begin{array}{l}\text { Incidence } \\
\text { rate }\end{array}$ & $\begin{array}{l}\text { New } \\
\text { cases }\end{array}$ & $\begin{array}{l}\text { Incidence } \\
\text { rate }\end{array}$ & $\begin{array}{l}\text { New } \\
\text { cases }\end{array}$ & $\begin{array}{l}\text { Incidence } \\
\text { rate }\end{array}$ \\
\hline $15-19$ & 1181 & 212.9 & 1038 & 198.1 & 2219 & 205.7 \\
\hline $20-24$ & 1810 & 321.6 & 1804 & 335.5 & 3614 & 328.4 \\
\hline $25-29$ & 2348 & 436.8 & 3079 & 584.8 & 5427 & 510.0 \\
\hline Total & 5339 & 322.6 & 5921 & 372.8 & 11260 & 347.2 \\
\hline
\end{tabular}

*Data source: Canadian Cancer Registry database, Statistics Canada.
Incidence for males and females varied by age. The proportion of males aged 15 to 19 years with a new diagnosis of cancer was slightly higher than the corresponding proportion of females, whereas the reverse was true among those aged 20 to 24 years. Females aged 25 to 29 years were one-third more likely than males to receive a diagnosis of cancer. The distribution of cancer types also differed between females and males 15 to 29 years of age (Table 2).

Relative to incidence, mortality for adolescents and young adults with cancer was lower. On average, 282 deaths per year were registered between 2001 and 2005, which corresponds to an annual mortality rate of 43.9 per million. During this period, the mortality rate was higher among males (46.9 per million) than among females (40.8 per million).

The five-year observed survival proportion for all cancers in adolescents and young adults was $85 \%$ for the period 2001-2005 (Table 3). The one-year observed survival proportion was $94 \%$, and the three-year value was $88 \%$. Among the cancers examined, the highest five-year observed survival proportions for common cancers in this age group were for thyroid cancer (99\%), testis cancer (96\%), Hodgkin lymphoma $(95 \%)$ and melanoma (93\%) whereas the lowest were for brain tumours $(68 \%)$ and leukemias $(68 \%)$.

For all cancers combined, the five-year observed survival proportion for females was higher than that for males (Table 4). Furthermore, survival among females was similar to, or higher than, survival among males for each of the most com-

Table 2: Percent distribution of leading types of cancer among adolescents and young adults (15-29 years), Canada, 2002-2006*

\begin{tabular}{lcc}
\hline & \multicolumn{2}{c}{ Sex; \% of cancers } \\
\cline { 2 - 3 } Type of cancer & Male & Female \\
& $n=5339$ & $n=5921$ \\
\hline Nonepithelial & & \\
Testis & 27 & NA \\
Hodgkin lymphoma & 14 & 12 \\
\hline Non-Hodgkin lymphomat & 9 & 5 \\
Leukemia & 9 & 6 \\
Central nervous system & 8 & 6 \\
\hline Melanoma & 6 & 11 \\
\hline Soft-tissue and other extraosseous & 5 & 4 \\
sarcoma & & \\
Bone & 4 & 2 \\
\hline Other nonepithelial & 3 & 4 \\
Epithelial & & \\
\hline Thyroid & 5 & 23 \\
\hline Cervix & NA & 7 \\
\hline Breast & NA & 7 \\
\hline Ovary & NA & 4 \\
Other epithelial & 10 & 9 \\
\hline Note: NA = not applicable. & & \\
*Data source: Canadian Cancer Registry database, Statistics Canada. \\
tNon-Hodgkin lymphoma includes Burkitt lymphoma and unspecified \\
lymphomas. & & \\
& & \\
\hline
\end{tabular}


mon cancers, with the differences being greatest for melanoma (96\% v. $87 \%)$ and non-Hodgkin lymphoma $(84 \%$ v. $75 \%$ ). Although there was no appreciable difference in five-year survival between those aged 25 to 29 years at diagnosis $(86 \%)$ and those 15 to 24 years $(85 \%)$, we observed several cancer site-specific differences. For cervical cancer, non-Hodgkin lymphoma, soft-tissue sarcoma and leukemia, survival was higher in the older age group, whereas the opposite was observed for brain tumours.

\section{Trends in incidence, mortality and survival}

The overall age-standardized cancer incidence rate for Canadian adolescents and young adults rose during the period 1997-2006, driven mostly by epithelial cancers such as cancers of the thyroid and female breast (Table 5). The overall annual percent change was $0.9 \%$ for males and $1.7 \%$ for females, with both rates of change being statistically significant. Long-term trends in incidence and mortality for specific cancer types are shown in Appendix 1 (available at www.cmaj.ca/cgi/content/full/cmaj $.100800 / \mathrm{DC} 1)$. The high survival rates for most cancer types in this age group are reflected by the large gap between incidence and mortality rates. Some cancer types, such as testis and thyroid cancer, showed strong upward incidence trends.

In contrast to incidence, the overall age-standardized cancer mortality rate for adolescents and young adults declined significantly between 1996 and 2005, by 3.2\% per year among males and $1.7 \%$ per year among females. The decline in overall mortality was driven mainly by decreases in the rates of leukemia in both sexes and of breast cancer in females (see Appendix 1).

For all cancers combined, survival for the period 2001-2005 was five percentage points greater than that observed for 1992 1996 (85\% v. 80\%) (Table 6). The biggest gains in survival were for non-Hodgkin lymphoma, leukemia and soft-tissue sarcoma.

\section{Cancers with significantly changing trends}

The incidence rate for testis cancer in adolescents and young adults rose significantly, by $2.7 \%$ per year, between 1997 and 2006. However, the mortality rate for this type of cancer is very low, and thus the five-year observed survival proportion, 96\%, was one of the highest among cancers in this age group.

The incidence rate for non-Hodgkin lymphoma was considerably higher among males than among females. The rate among young females declined significantly, by $2.8 \%$ per year. In contrast, the rate among males declined significantly before 2001 and then increased nonsignificantly after 2001, with mortality rates roughly reflecting the trend in incidence. This group of cancers has one of the largest differences in observed survival between males and females (75\% v. $84 \%$ ) that is not explained by HIV infection.

The incidence rate for soft-tissue sarcoma among young males has risen since 2001, following a long, steep decline. Among females, however, the rate was stable over the same period. As with non-Hodgkin lymphoma, this cancer has a notable difference in observed survival between males and females $(70 \%$ v. $75 \%)$ not explained by HIV-associated Kaposi sarcoma.

The incidence of thyroid cancer was more than four times higher among young females than among young males. Although rates increased in both sexes, the upward trend was much stronger among females $(7.1 \%$ per year). The mortality rate for this cancer is low, and the five-year observed survival was one of the highest among adolescents and young adults: $98 \%$ for males and $100 \%$ for females.

The incidence rate of cervical cancer declined by more than 3\% per year between 1997 and 2006, probably because of increased uptake of Papanicolaou smear (Pap) testing and follow-up treatment among young females.

Table 3: Observed survival for selected cancers in adolescents and young adults (15-29 years), by survival duration, Canada (excluding Quebec), 2001-2005*

\begin{tabular}{|c|c|c|c|}
\hline \multirow[b]{2}{*}{ Type of cancer } & \multicolumn{3}{|c|}{ Duration of survival; $\%$ surviving $(95 \% \mathrm{Cl})$} \\
\hline & $1 \mathrm{yr}$ & $3 \mathrm{yr}$ & $5 \mathrm{yr}$ \\
\hline All cancers & 94 (94-95) & $88(87-88)$ & $85(84-86)$ \\
\hline Thyroid & $100(99-100)$ & $99(99-100)$ & $99(99-100)$ \\
\hline Testis & 99 (98-99) & $96(95-97)$ & $96(94-97)$ \\
\hline Hodgkin lymphoma & $99(99-100)$ & $96(95-97)$ & $95(93-96)$ \\
\hline Melanoma & $98(97-99)$ & 95 (94-96) & $93(91-94)$ \\
\hline Cervix & $96(94-97)$ & $89(86-92)$ & $88(84-91)$ \\
\hline Non-Hodgkin lymphomat & $87(85-90)$ & $80(77-83)$ & $79(75-82)$ \\
\hline Breast & 97 (94-98) & $83(78-87)$ & $75(69-79)$ \\
\hline Soft-tissue and other extraosseous sarcoma & $90(86-93)$ & $77(72-81)$ & $72(68-77)$ \\
\hline Brain and other nervous system & $89(86-91)$ & $76(73-80)$ & $68(64-71)$ \\
\hline Leukemia & $85(81-87)$ & $72(68-75)$ & $68(64-71)$ \\
\hline
\end{tabular}

Note: $\mathrm{Cl}=$ confidence interval.

*Data source: Canadian Cancer Registry database, Statistics Canada. Data from Quebec were excluded, in part, because the method for ascertaining the date of cancer diagnosis in that province differs from the method used by other provinces and territories and because of issues in correctly ascertaining the vital status of cases. tNon-Hodgkin lymphoma includes Burkitt lymphoma and unspecified lymphomas. 


\section{Interpretation}

\section{International comparisons}

Most major cancers occurring in adolescents and young adults are found consistently across developed countries, with only small differences in the distribution of individual types. ${ }^{12,13}$ The increase in incidence rate over time among adolescents and young adults in Canada is similar to that reported for youth aged 13 to 24 years in most European countries ${ }^{12,14}$ and those aged 15 to 29 years in the United States. ${ }^{13}$

The incidence of testis cancer has been increasing among Canadian males for several decades for reasons that are not well understood. The rising incidence of testicular cancer has been reported in many industrialized countries, mostly in males aged 20-24 years. ${ }^{15,16}$ The only established risk factor for testicular cancer is cryptorchidism, which accounts for a small proportion of cases. ${ }^{17}$ The nonsignificant rise in non-Hodgkin lymphoma among Canadian males is also not well understood. Immunosuppression is the clearest risk factor for non-Hodgkin lymphoma but accounts for only a small fraction of cases. ${ }^{17}$

As in Canada, the incidence of thyroid cancer among older adolescents has risen in England and Scotland..$^{18}$ In these places, the increase has been considerably greater than the rate of increase among US youth 15-24 years, ${ }^{13}$ although the overall incidence in England was lower than in the United States.

We estimated the five-year observed survival for Canadian adolescents and young adults aged 15 to 29 years at the time of cancer diagnosis at $85 \%$ for the period 2001-2005. Overall five-year observed survival for Europeans aged 15 to 24 years at diagnosis for the period 1995-2002 was recently reported as $87 \%$, ranging from $84 \%$ in Northern Ireland to $92 \%$ in
Italy.$^{19}$ Both the Canadian and European studies showed improvements in survival over recent years. In the United States, the Surveillance, Epidemiology and End Results Program of the National Cancer Institute found improvements in survival over a longer period (1975-2000) for those 15 to 29 years of age. ${ }^{13}$ In some regions of the world, researchers have suspected that improvements in survival among adolescents and young adults are linked to medical insurance and treatment adherence, such that smaller improvements may be attributable to a lack of insured medical care and low compliance with treatment. ${ }^{20,21}$ Finally, Canadian, US and European data all indicate that survival is generally better for young females than young males, which could be related to the distribution of cancer types between the sexes..$^{13,19}$

\section{Other health care issues}

\section{Prevention and screening}

Previous research has suggested that nonepithelial cancer is more likely to be related to viral infection, radiation, genetic predisposition and chemical carcinogens in the environment. ${ }^{17,22}$ In contrast, epithelial cancer is more likely to be related to tobacco or alcohol abuse, diet and physical inactivity, all of which have an effect over many years. Pap smear testing is the only example of organized screening for adolescents and young adults, for whom few other cancer screening options currently exist.

Among the few known or strongly suspected risk factors for cancer in adolescents and young adults, congenital anomalies (e.g., undescended testicle) or a family history of cancer appears to be associated with a risk for certain cancers (e.g.,

Table 4: Five-year observed survival for selected cancers in adolescents and young adults (15-29 years), by sex and age group, Canada (excluding Quebec), 2001-2005*

\begin{tabular}{lcccc}
\hline & \multicolumn{3}{c}{ Sex or age group; \% surviving (95\% Cl) } \\
\cline { 2 - 5 } Type of cancer & Male & Female & $15-24 \mathrm{yr}$ & $25-29 \mathrm{yr}$ \\
\hline All cancers & $82(81-84)$ & $87(86-88)$ & $85(84-87)$ & $86(85-87)$ \\
Thyroid & $98(95-99)$ & $100(99-100)$ & $100(99-100)$ & $99(98-100)$ \\
Testis & $96(94-97)$ & NA & $95(93-96)$ & $96(94-98)$ \\
Hodgkin lymphoma & $95(92-96)$ & $95(93-96)$ & $94(92-96)$ & $95(93-97)$ \\
Melanoma & $87(83-90)$ & $96(94-97)$ & $93(90-95)$ & $92(89-94)$ \\
Cervix & NA & $88(84-91)$ & $82(73-89)$ & $89(86-92)$ \\
$\begin{array}{l}\text { Non-Hodgkin } \\
\text { lymphomat }\end{array}$ & $75(70-79)$ & $84(78-88)$ & $77(72-81)$ & $81(75-85)$ \\
$\begin{array}{l}\text { Breast } \\
\text { Soft-tissue and other } \\
\text { extraosseous sarcoma }\end{array}$ & $70(63-76)$ & $75(68-80)$ & $71(65-77)$ & $74(66-80)$ \\
$\begin{array}{l}\text { Brain and other } \\
\text { nervous system }\end{array}$ & $64(59-69)$ & $71(66-76)$ & $72(67-77)$ & $61(55-67)$ \\
Leukemia & $66(61-71)$ & $70(64-75)$ & $66(62-71)$ & $71(63-77)$ \\
\hline
\end{tabular}

Note: $\mathrm{Cl}=$ confidence interval, $\mathrm{ES}=$ estimate suppressed because of high standard error $(>0.05), \mathrm{NA}=$ not applicable.

*Data source: Canadian Cancer Registry database, Statistics Canada. Data from Quebec were excluded, in part, because the method for ascertaining the date of cancer diagnosis in that province differs from the method used by other provinces and territories and because of issues in correctly ascertaining the vital status of cases.

tNon-Hodgkin lymphoma includes Burkitt lymphoma and unspecified lymphomas. 
testis, breast, colorectal). Exposure to infectious agents such as human papillomavirus, HIV and Epstein-Barr virus may increase the risk for other diseases such as cervical cancer, Kaposi sarcoma, and Hodgkin and non-Hodgkin lymphoma. ${ }^{23}$ Exposure to known carcinogens before birth or during childhood and treatment with chemotherapy and/or radiotherapy during childhood have also been linked to cancer in adolescence and young adulthood. ${ }^{23}$ The International Agency for Research on Cancer has recently classified exposure to ultraviolet radiation through the use of tanning beds and sunlamps as carcinogenic, ${ }^{24}$ a risk factor for melanoma that may be especially relevant for young people. ${ }^{25}$

Although our knowledge of the risk factors for cancer in adolescents and young adults is limited, the care of this population should include a focus on preventing modifiable risk factors that typically start or intensify during this stage of development and that can affect current cancer risk, as well as cancer risk later in life. Such modifiable risk factors include tobacco, alcohol, excess sun exposure and some sexually transmitted diseases.

\section{Diagnosis}

Cancers in adolescents and young adults may not be detected until later in their course, because young people who experience symptoms may delay seeking medical help or may not have access to routine medical care that could allow prompt

Table 5: Annual percent change in age-standardized incidence rates for selected cancers in adolescents and young adults (15-29 years), by sex, Canada, 1997-2006*

\begin{tabular}{|c|c|c|}
\hline \multirow[b]{2}{*}{ Type of cancer } & \multicolumn{2}{|c|}{ Sex; annual $\%$ changet } \\
\hline & Male & Female \\
\hline All cancers $\ddagger$ & 0.99 & 1.79 \\
\hline Nonepithelial & 0.8 & -0.1 \\
\hline Hodgkin lymphoma & -0.3 & -1.1 \\
\hline Testis & $2.7 * *$ & NA \\
\hline Melanoma & -2.1 & 1.0 \\
\hline Central nervous system & -0.6 & 1.5 \\
\hline Leukemia & 1.9 & 0.0 \\
\hline $\begin{array}{l}\text { Non-Hodgkin } \\
\text { lymphoma§ }\end{array}$ & $2.5+t$ & $-2.8 \rrbracket$ \\
\hline $\begin{array}{l}\text { Soft-tissue and other } \\
\text { extraosseous sarcoma }\end{array}$ & $6.4+\dagger$ & -0.8 \\
\hline Epithelial & 1.3 & 3.39 \\
\hline Thyroid & 3.0 & 7.19 \\
\hline Cervix & NA & $-3.4 \pi$ \\
\hline Breast & NA & 2.4 \\
\hline
\end{tabular}

Note: NA = not applicable.

*Data source: Canadian Cancer Registry database, Statistics Canada.

tCalculation of annual percent change assumes a log-linear model. For all cancer types, change points were fit to incidence rates from 1992 to 2006. \#"All cancers" includes other cancers not listed in this table but excludes non-melanoma skin cancer (basal and squamous).

$\S N o n-H o d g k i n$ lymphoma includes Burkitt lymphoma and unspecified lymphomas.

ПSignificant at $p=0.01$

$* *$ Significant at $p=0.05$.

t†For these two types of cancer in males, the slope of the trend changed after 1997, and 2001 was the change point (the baseline year). detection of disease. Physicians may also be less familiar with the signs and symptoms of cancer in adolescents and young adults. The symptoms may instead be attributed to fatigue, stress or other causes. A report by the Canadian Childhood Cancer Surveillance and Control Program found that adolescents aged 15 to 19 years were more likely than children to have a delayed cancer diagnosis. ${ }^{26}$ Furthermore, the delay was more prominent among adolescents referred to adult cancer centres than among those referred to children's hospitals.

\section{Treatment}

Cancers in adolescents and young adults may have biologically distinct behaviours, and the same cancers in different age groups may respond differently to treatment. ${ }^{27}$ For example, cancers common in adolescents such as acute myeloid leukemia, acute lymphoblastic leukemia, rhabdomyosarcoma and Ewing sarcoma are associated with lower five-year survival for adolescents than for children under 15 years of age. The biology of the cancer and the patient's tolerance for chemotherapy may change unfavourably in late adolescence and young adulthood relative to childhood, which affects both the ability to deliver effective therapy and the likelihood of a successful outcome. ${ }^{27}$

The relative rarity of cancers in adolescents and young adults means that patients tend to be treated in many different centres. Consequently, few institutions develop the required expertise, infrastructure or clinical trial opportunities for better

Table 6: Five-year survival for selected cancers in adolescents and young adults (15-29 years), by calendar period, Canada (excluding Quebec)*

\begin{tabular}{lcc}
\hline & \multicolumn{2}{c}{$\begin{array}{c}\text { Calendar period; } \\
\% \text { surviving }(95 \% \mathrm{Cl})\end{array}$} \\
\cline { 2 - 3 } Type of cancer & $1992-1996+$ & $2001-2005 \ddagger$ \\
\hline All cancers & $80(79-81)$ & $85(84-86)$ \\
\hline Thyroid & $100(99-100)$ & $99(99-100)$ \\
Testis & $94(92-95)$ & $96(94-97)$ \\
\hline Hodgkin lymphoma & $94(93-96)$ & $95(93-96)$ \\
Melanoma & $93(91-94)$ & $93(91-94)$ \\
Cervix & $86(83-89)$ & $88(84-91)$ \\
Non-Hodgkin lymphoma§ & $65(61-69)$ & $79(75-82)$ \\
Breast & $70(65-75)$ & $75(69-79)$ \\
Soft-tissue and other & $64(59-69)$ & $72(68-77)$ \\
extraosseous sarcoma & & $68(64-71)$ \\
Brain and other nervous & $63(59-67)$ & $68(64-71)$ \\
\hline system & & \\
Leukemia & $56(51-60)$ & \\
\hline
\end{tabular}

Note: $\mathrm{Cl}=$ confidence interval.

* Data source: Canadian Cancer Registry database, Statistics Canada. Data from Quebec were excluded, in part, because the method for ascertaining the date of cancer diagnosis differed from the method used by other provinces and territories and because of issues in correctly ascertaining the vital status of cases.

tSurvival for 1992-1996 was based on the cohort method.

¥Survival for 2001-2005 was based on the period method; as such, these data represent predicted survival.

$\S$ Non-Hodgkin Lymphoma includes Burkitt lymphoma and unspecified lymphomas. 
management of young cancer patients, as indicated by evidence of better survival rates among adolescents and young adults at health care centres where these factors are more readily available. ${ }^{28,29}$ The multidisciplinary expertise concentrated at specialized centres can include experienced surgeons, radiation oncologists and medical oncologists, as well as supportive care teams involving social workers, psychologists, education officers, physiotherapists and occupational therapists.

In Canada, the majority of pediatric tertiary care centres have age limits between 16 and 18 years for inpatient admission. These centres typically offer supportive care focused on the family, as well as long-term follow-up and transitioning programs to adult health care. However, they have little experience in the management of the cancers that are found more commonly in adolescents and young adults. For older adolescent patients who are treated in pediatric centres, the transition from pediatric to adult care settings must involve collaboration among the young patient, his or her family, and health care providers to create an individualized care plan. ${ }^{30}$

The pediatric care setting does, however, offer several benefits, such as greater access to clinical trials, peer support and more intensive treatment. Management in pediatric settings often consists of combined-modality approaches incorporating multiagent chemotherapy, high-dose radiotherapy and aggressive surgery, which adolescents and young adults are likely better able to tolerate relative to older adults. ${ }^{3} \mathrm{How}-$ ever, the majority of older Canadian adolescents currently do not benefit from this strategy because they are treated in adult facilities. ${ }^{26}$ According to data from the Pediatric Oncology Group of Ontario and the Ontario Cancer Registry for the period 1997-2001, only 32\% of cancer patients 15 to 17 years of age were treated in a pediatric oncology centre in Ontario; the remainder were treated in adult facilities. ${ }^{31}$ Differences have also been noted in the United States, where only about $20 \%$ of patients 15 to 19 years old are treated at pediatric or adult cooperative group institutions. In contrast, about $95 \%$ of children are treated in these cooperative settings. ${ }^{32,33}$

\section{Clinical trials}

For some malignant diseases, participation in a clinical trial is often associated with better survival among children under the age of 15 years. ${ }^{34}$ Participation in such trials by adolescents and young adult cancer patients is low. ${ }^{35}$ Participation in a trial under the care of an oncology specialist likely confers a stricter discipline to the treatment protocol by both physician and patient, as well as better adherence to drug dosages and schedules. It also offers the supportive care expertise intrinsic to the clinical trial environment. ${ }^{36}$ It is estimated that only $10 \%$ to $20 \%$ of Canadian adolescents with cancer participate in clinical trials ${ }^{26}$ whereas nearly $60 \%$ of children in the United States do so. ${ }^{35}$

This lack of participation in clinical trials has been attributed to a variety of factors. For example, there is a paucity of suitable trials for the forms of cancer that commonly occur in adolescents and young adults, and adequate sample sizes must be accrued to achieve statistical power. In addition, adolescents and young adults may be less inclined to participate in a clinical trial, even if such an opportunity is offered. Clin- icians and patients may not be aware of opportunities for clinical trials, and clinicians may view adolescents and young adults as likely to be noncompliant with protocol requirements. ${ }^{32}$ The age eligibility restrictions of certain trials or of certain hospitals exclude some adolescents and young adults. ${ }^{37}$ Finally, few adolescents and young adults are treated in cooperative treatment settings, where more clinical trials are typically available.

\section{Follow-up care}

Quality of life and the late effects of cancer treatment have become increasingly important as the prevalence of cancers among Canadian adolescents and young adults continues to increase. Community-based care is challenging because it demands that primary care physicians have knowledge of and expertise in specific cancer treatments, as well as in optimal clinical surveillance and management. Treatment-related developmental delays and infertility are just two examples of medical needs that community physicians encounter when they are managing young cancer survivors. ${ }^{38}$

Because the majority of young adult cancer survivors receive care outside of a cancer centre, educating them about their disease and the need for lifelong follow-up care is imperative. A shared-care model, whereby coordination exists between specialists and community-based health care professionals in caring for adolescents and young adults in the community, can address gaps in care outside of the tertiary care setting.

\section{Efforts to reduce gaps in care}

In the United Kingdom and the United States, national task forces have been established to reduce the disparity in cancer outcomes between adolescents and young adults and other age groups. The UK Children's Cancer Study Group and the Children's Oncology Group (North America, Australia and New Zealand) have made advances through collaboration with adult cooperatives in extending the upper age limit for pediatric clinical trials and opening adult trials to young patients with selected tumours. ${ }^{39,40}$ Some trials undertaken by the Children's Oncology Group now include patients up to 50 years of age. ${ }^{41}$

In the United Kingdom, eight cancer units for teenagers have been established since the late 1990s. These centres are staffed by physicians and nurses with expertise in caring for adolescent and young adult patients, and provide a greater focus on their patients' physical and psychological needs. ${ }^{42,43}$

In the United States, the Children's Oncology Group formed its Adolescent and Young Adult Committee in 2000 to research obstacles to participation in clinical trials and to identify the best diagnostic methods and treatments for cancers in adolescents and young adults. Three strategy groups are addressing key areas such as cancer-specific clinical trials, behavioural oncology, and research in epidemiology and health services. In addition, the group aims to develop strategies that will improve adherence to prescribed regimens, conduct research on psychosocial support, prevent treatmentrelated sequelae, increase continuity of care as adolescents transition into adulthood, and increase knowledge and prac- 
tice of healthy dietary and physical exercise habits among young cancer patients.

In 2008, a national task force was established as a collaboration between the Canadian Partnership Against Cancer and $\mathrm{C} 17$, the consortium of all pediatric oncology centres in Canada. The mission of the task force is to ensure prompt, equitable access to the best care for adolescents and young adults with cancer and to establish and support research to identify how their health outcomes and health-related quality of life can be optimized.

Among other activities, the working groups of the task force are expected to report on patterns and transition models of long-term follow-up of survivors of cancer in childhood, adolescence and young adulthood; make recommendations for the provision of health care to cancer survivors in this age group, to improve their quality of life; and develop lines of communication between pediatric and adult health care providers, as well as other influential parties, to promote continuing improvement in the health care provided to young cancer patients.

These activites formed the framework for an international workshop in early 2010 hosted by the task force and other stakeholder groups, with the goal of providing a set of recommendations and an apparatus for promoting their sustainable implementation. In some measure, these aims accord with those of the Progress Review Group on adolescent and young adult oncology that was convened by the US National Cancer Institute in a unique partnership with the Lance Armstrong Foundation. ${ }^{37}$ Somewhat related agendas are being pursued by the Teenage Cancer Trust in the United Kingdom and by CanTeen in Australia.

Other areas for future consideration are the geographic centralization of health care services for adolescents and young adults, consistent with the existing model for pediatric cancer care and similar to centres being developed in the United Kingdom through the Teenage Cancer Trust, which has created a distinct system of care for adolescents and young adults. ${ }^{44}$ In addition, the experience of hospices for adolescents is limited, and there is a need to fill the gap in information on the optimal provision of palliative and end-oflife care for young people with cancer. ${ }^{45}$

\section{Surveillance and research}

Publication of major reports from the Progress Review Group $^{37}$ and the Surveillance, Epidemiology and End Results Program $^{13}$ of cancer rates in adolescents and young adults in the United States has stimulated greater recognition of the distinct needs and lagging care of adolescents and young adults in North America. Momentum has been building as new research continues to expand our understanding of cancer in adolescents and young adults, including quality of life, survival challenges and access to care and treatment. Additionally, models of care such as those of the UK Teenage Cancer Trust are becoming more widely available in other countries. An ongoing challenge will be to develop a comprehensive set of data elements for surveillance that will aid in advancing preventive, therapeutic and health services-related research for this age group. Furthermore, our limited under- standing of risk factors will continue to be an impetus for greater research into this subject.

\section{Implications for physicians}

The specialized care of adolescents and young adults requires consideration of the unique stage of their physical, intellectual and emotional development, as well as age-specific issues related to socialization, education, emotional support and adherence to treatment regimens. ${ }^{46}$ Some young cancer patients and survivors face unique challenges to their selfesteem and identity development, psychological distress and fear of recurrence. ${ }^{47-49}$

Several challenges must be overcome to improve the coordination and quality of care for this age group. First, cancer should more regularly be considered as a possible diagnosis among adolescents and young adults and their health care providers. Second, the rapidly growing and aggressive nature of some of the curable cancers in adolescents and young adults, such as testis cancer and non-Hodgkin lymphoma, necessitates prompt referral to specialist care to take advantage of comprehensive treatment and access to cooperative group clinical trials. ${ }^{34}$ Progress is also needed in the development of therapeutic and monitoring guidelines for adolescents and young adults. ${ }^{35}$ Third, care provided in same-age peer settings allows patients to observe others with whom they can relate and to address areas of concern such as coping with uncertainty, dependency versus autonomy, social exclusion, separation processes, body image, intimacy, sexuality and fertility, and career plans. ${ }^{50,51}$ Finally, coordination of hospital and community care for young survivors can support their proper reintegration into society following successful treatment.

\section{This article has been peer reviewed.}

Competing interests: Ronald Barr has received grants from the Public Health Agency of Canada, has received royalties from Springer-Verlag for for coediting a book and has received reimbursement for travel expenses from the Teenage Cancer Trust (UK) and the Canadian Adolescent and Young Adult Task Force. None declared for all other authors.

Contributors: Prithwish De conceptualized the article. Larry Ellison and Robert Semenciw acquired and analyzed the data. All authors contributed to the interpretation of the data. Prithwish De, Ronald Barr, Larry Ellison, Loraine Marrett, Hannah Weir, Dagny Dryer and Eva Grunfeld drafted the text. All authors provided critical revision of the article and approved the final version to be published.

Disclaimer: The findings and conclusions in this report are those of the authors and do not necessarily represent the official position of the Canadian Association of Provincial Cancer Agencies, Canadian Cancer Society, Cancer Care Nova Scotia, Cancer Care Ontario, McMaster University, Ontario Institute for Cancer Research, PEI Cancer Treatment Centre, Public Health Agency of Canada, Statistics Canada or the US Centers for Disease Control and Prevention, with which the authors and members of the Steering Committee for Canadian Cancer Statistics are affiliated.

\section{REFERENCES}

1. Barr RD, Holowaty EJ, Birch JM. Classification schemes for tumors diagnosed in adolescents and young adults. Cancer 2006;106:1425-30.

2. Canadian Cancer Society, Steering Committee. Canadian cancer statistics 2009 Toronto (ON): The Society; 2009.

3. Bleyer A. Young adult oncology: the patients and their survival challenges. $C A$ Cancer J Clin 2007;57:242-55.

4. Birch JM, Alston RD, Kelsey AM, et al. Classification and incidence of cancers in adolescents and young adults in England 1979-1997. Br J Cancer 2002:87:1267-74.

5. Demographic estimates compendium 2008. Ottawa (ON): Statistics Canada; 2009. Cat no $91-213-S C B$. 
6. Brenner H, Gefeller O. Deriving more up-to-date estimates of long-term patient survival. J Clin Epidemiol 1997;50:211-6.

7. Ellison LF, Gibbons L. Survival from cancer - up-to-date predictions using period analysis. Health Rep 2006;17:19-30.

8. Ellison LF. An empirical evaluation of period survival analysis using data from the Canadian Cancer Registry. Ann Epidemiol 2006;16:191-6.

9. Brenner H. Up-to-date survival curves of children with cancer by period analysis. Br J Cancer 2003;88:1693-7.

10. Brenner H, Gefeller O, Hakulinen T. Period analysis for 'up-to-date' cancer survival data: theory, empirical evaluation, computational realisation and applications. Eur J Cancer 2004;40:326-35.

11. Talback M, Stenbeck M, Rosen M. Up-to-date long-term survival of cancer patients: an evaluation of period analysis on Swedish Cancer Registry data. Eur J Cancer 2004;40:1361-72.

12. Steliarova-Foucher E, Stiller C, Kaatsch P, et al. Geographical patterns and time trends of cancer incidence and survival among children and adolescents in Europe since the 1970s (the ACCIS project): an epidemiological study. Lancet 2004; 364:2097-105.

13. Bleyer A, O'Leary M, Barr R, et al., editors. Cancer epidemiology in older adolescents and young adults 15 to 29 years of age, including SEER incidence and survival: 1975-2000. Bethesda (MD): National Cancer Institute; 2006.

14. Alston RD, Geraci M, Eden TO, et al. Changes in cancer incidence in teenagers and young adults (ages 13 to 24 years) in England 1979-2003. Cancer 2008; 113:2807-15.

15. Pearce MS, Parker L, Windebank KP, et al. Cancer in adolescents and young adults aged 15-24 years: a report from the North of England young person's malignant disease registry, UK. Pediatr Blood Cancer 2005;45:687-93.

16. Huyghe E, Matsuda T, Thonneau P. Increasing incidence of testicular cancer worldwide: a review. J Urol 2003;170:5-11.

17. Schottenfeld D, Fraumeni J. Cancer epidemiology and prevention. London (UK): Oxford University Press; 2006.

18. Reynolds RM, Weir J, Stockton DL, et al. Changing trends in incidence and mortality of thyroid cancer in Scotland. Clin Endocrinol (Oxf) 2005;62:156-62.

19. Gatta G, Zigon G, Capocaccia R, et al. Survival of European children and young adults with cancer diagnosed 1995-2002. Eur J Cancer 2009;45:992-1005.

20. Gesundheit B, Greenberg M, Or R, et al. Drug compliance by adolescent and young adult cancer patients: challenges for the physician. In: Bleyer WA, Barr RD, editors. Cancer in adolescents and young adults. Heidelberg (Germany): Springer; 2007. p. 353-364.

21. Freyer DR, Barr RD. Making ends meet: financial issues from the perspectives of patients and their healthcare team. In: Bleyer WA, Barr RD, editors. Cancer in adolescents and young adults. Heidelberg (Germany): Springer; 2007. p. 493-504.

22. Baron JA, Bergstrom R, Lindgren C, et al. Trends in non-epithelial cancer incidence in Denmark, Finland, and Sweden, 1961-1990. Int J Cancer 1996;67:648-52.

23. Bleyer A, Viny A, Barr R. Cancer in 15- to 29-year-olds by primary site. Oncologist 2006;11:590-601.

24. El Ghissassi F, Baan R, Straif K, et al. A review of human carcinogens - part D radiation. Lancet Oncol 2009;10:751-2.

25. Gallagher RP, Spinelli JJ, Lee TK. Tanning beds, sunlamps, and risk of cutaneous malignant melanoma. Cancer Epidemiol Biomarkers Prev 2005;14:562-6.

26. Klein-Geltink J, Shaw AK, Morrison HI, et al. Use of paediatric versus adult oncology treatment centres by adolescents 15-19 years old: the Canadian Childhood Cancer Surveillance and Control Program. Eur J Cancer 2005;41:404-10.

27. Bleyer A, Barr R, Hayes-Lattin B, et al. The distinctive biology of cancer in adolescents and young adults. Nat Rev Cancer 2008;8:288-98.

28. Halm EA, Lee C, Chassin MR. Is volume related to outcome in health care? A systematic review and methodologic critique of the literature. Ann Intern Med 2002 137:511-20.

29. Hillner BE, Smith TJ, Desch CE. Hospital and physician volume or specialization and outcomes in cancer treatment: importance in quality of cancer care. J Clin Oncol 2000;18:2327-40.

30. Rosen DS, Blum RW, Britto M, et al. Transition to adult health care for adolescents and young adults with chronic conditions: position paper of the Society for Adolescent Medicine. J Adolesc Health 2003;33:309-11.

31. Greenberg ML, Barr RD, DiMonte B, et al. Childhood cancer registries in Ontario,
Canada: lessons learned from a comparison of two registries. Int J Cancer 2003; 20:88-91.

32. Bleyer WA, Tejeda H, Murphy SB, et al. National cancer clinical trials: children have equal access; adolescents do not. J Adolesc Health 1997;21:366-73.

33. Rogers AS. Adolescent under enrollment in national clinical research: it is time to ask why. J Adolesc Health 1997;21:374-5.

34. Meadows AT, Kramer S, Hopson R, et al. Survival in childhood acute lymphocytic leukemia: effect of protocol and place of treatment. Cancer Invest 1983;1:49-55.

35. Bleyer A, Budd T, Montello M. Adolescents and young adults with cancer: the scope of the problem and criticality of clinical trials. Cancer 2006;107:1645-55.

36. Bleyer WA. Cancer in older adolescents and young adults: epidemiology, diagnosis, treatment, survival, and importance of clinical trials. Med Pediatr Oncol 2002 38:1-10.

37. National Cancer Institute. Closing the gap: research and care imperatives for adolescents and young adults with cancer. Report of the Adolescent and Young Adult Oncology Progress Review Group. Bethesda (MD): The Institute; 2006.

38. Freyer DR, Kibrick-Lazear R. In sickness and in health: transition of cancer-related care for older adolescents and young adults. Cancer 2006;107:1702-9.

39. Bleyer A, Morgan S, Barr R. Proceedings of a workshop: bridging the gap in care and addressing participation in clinical trials. Cancer 2006;107:1656-8.

40. Ferrari A, Montello M, Budd T, et al. The challenges of clinical trials for adolescents and young adults with cancer. Pediatr Blood Cancer 2008;50:1101-4.

41. Thomas DM, Seymour JF, O'Brien T, et al. Adolescent and young adult cancer: A revolution in evolution? Intern Med J 2006;36:302-7.

42. Lewis IJ. Cancer in adolescence. Br Med Bull 1996;52:887-97.

43. Whelan J. Where should teenagers with cancer be treated? Eur J Cancer 2003;39: 2573-8.

44. Whiteson M. The Teenage Cancer Trust - advocating a model for teenage cancer services. Eur J Cancer 2003;39:2688-93

45. Klopfenstein KJ, Hutchison C, Clark C, et al. Variables influencing end-of-life care in children and adolescents with cancer. J Pediatr Hematol Oncol 2001;23: 481-6.

46. Ritchie MA. Psychosocial functioning of adolescents with cancer: a developmental perspective. Oncol Nurs Forum 1992;19:1497-501.

47. Zebrack BJ, Gurney JG, Oeffinger K, et al. Psychological outcomes in long-term survivors of childhood brain cancer: a report from the childhood cancer survivor study. J Clin Oncol 2004;22:999-1006.

48. Bello LK, McIntire SN. Body image disturbances in young adults with cancer. Implications for the oncology clinical nurse specialist. Cancer Nurs 1995;18:138-43.

49. Daiter S, Larson RA, Weddington WW, et al. Psychosocial symptomatology, personal growth, and development among young adult patients following the diagnosis of leukemia or lymphoma. J Clin Oncol 1988;6:613-7.

50. Stevens B, Kagan S, Yamada J, et al. Adventure therapy for adolescents with cancer. Pediatr Blood Cancer 2004;43:278-84.

51. Thaler-DeMers D. Intimacy issues: sexuality, fertility, and relationships. Semin Oncol Nurs 2001;17:255-62.

Correspondence to: Dr. Prithwish De, Canadian Cancer Society, 10 Alcorn Ave., Ste 200, Toronto ON M4V 3B1; pde@cancer.ca

Steering Committee for Canadian Cancer Statistics: Loraine D. Marrett (chair), Cancer Care Ontario; Prithwish De, Canadian Cancer Society; Dagny Dryer, PEI Cancer Treatment Centre; Larry F. Ellison, Statistics Canada; Eva Grunfeld, Ontario Institute for Cancer Research; Heather Logan, Canadian Association of Provincial Cancer Agencies; Maureen MacIntyre, Cancer Care Nova Scotia; Les Mery, Public Health Agency of Canada; Hannah K. Weir, US Centers for Disease Control and Prevention. 